\title{
Pressure pain thresholds in chronic migraine associated with hypertension
}

\author{
O Grosu*, S Odobescu, L Rotaru, I Moldovanu \\ From The European Headache and Migraine Trust International Congress \\ London, UK. 20-23 September 2012
}

\section{Introduction}

Studies on pain thresholds in migraine populations are contradictory and have not used algometry.

\section{Objectives}

To evaluate pressure pain thresholds (PPT) in chronic migraine patients associated with arterial hypertension $(\mathrm{Mg}+\mathrm{AHT})$ and without hypertension (Mg-AHT) .

\section{Methods}

Study consisted of 40 chronic migraine (CM) patients divided in 2 groups: $\mathrm{Mg}+\mathrm{AHT}-18$ pts (mean age 46.19 \pm 6.77 years), Mg-AHT - 22 pts (mean age $40.77 \pm$ 12.0 years), and 10 healthy controls (mean age $37.56 \pm$ 10.45 years). PPT were obtained bilaterally by mechanical pressure algometry from 15 anatomic points (ophthalmic nerve, temporalis muscle, median nerve, radial nerve, ulnar nerve, Achilles tendon, thenar eminence, suboccipital muscle insertions, trapezius muscle, supraspinatus muscle, second rib, lateral epicondyle, gluteal, great trochanter, knee) using Somedic algometer (SBMEDIC electronics, Sweden). Pressure algometry was applied three times on the same point and pain threshold was calculated as an average value.

\section{Results}

The mean PPT value for all 15 examined points was higher in $\mathrm{Mg}+\mathrm{AHT}$ vs. $\mathrm{Mg}$-AHT group (447.36 \pm 112.32 vs. $377.67 \pm 77.71, \mathrm{p}<0.05$ ) but didn't differ from the control group. In Mg-AHT group PPT was lower compared to $\mathrm{Mg}+\mathrm{AHT}$ and control group $(377.67 \pm 77.71$ vs. 437.00 $\pm 81.86, \mathrm{p}<0.05)$. In the Mg+AHT pts PPT was higher than in Mg-AHT group for eight application points (53.3\%): radial nerve, ulnar nerve, Achilles tendon, thenar eminence, trapezius muscle, supraspinatus muscle, greater trochanter and gluteal. In Mg- AHT group PPT was lower than healthy controls for seven application points (46.6\%): radial nerve, Achilles tendon, thenar eminence, greater trochanter, lateral epicondyle, gluteal and knee.

\section{Conclusion}

The arterial hypertension is associated with the increase of pain pressure thresholds evaluated by algometry in chronic migraine with hypertension patients and interacts with hyperalgesia and allodynia phenomena induced by chronic migraine through central and peripheral sensitization mechanisms.

Published: 21 February 2013

\section{Reference}

1. Fernandes de las Penas C, Madeleine P, Cuadrado ML, Ge HY, ArendtNielsen L, Pareja JA: Pressure pain sensitivity mapping of the temporalis muscle revealed bilateral pressure hyperalgesia in patients with strictly unilateral migraine. Cephalalgia 2009, 29:670-676.

doi:10.1186/1129-2377-14-S1-P128

Cite this article as: Grosu et al:: Pressure pain thresholds in chronic migraine associated with hypertension. The Journal of Headache and Pain 2013 14(Suppl 1):P128.
Submit your manuscript to a SpringerOpen ${ }^{\bullet}$ journal and benefit from:

- Convenient online submission

- Rigorous peer review

- Immediate publication on acceptance

- Open access: articles freely available online

- High visibility within the field

- Retaining the copyright to your article 